ISSN: 2091-0657 (Print); 2091-0673 (Online)

Open Access

\title{
Intra-articular lignocaine as a means of analgesia during manual reduction of acute anterior shoulder dislocation
}

\author{
Manoj Kandel, Shrawan Kumar Thapa, Rudra Marasini , Sushil Thapa, Shankar Dhakal, Robin \\ Shrestha \\ Department of Orthopaedics, Government Hospital, Bharatpur, Chitwan
}

\author{
Correspondence \\ Dr. Manoj Kandel \\ Department of Orthopaedics, \\ Government Hospital, \\ Bharatpur, Chitwan

\section{Email:} \\ manojkandel17@gmail.com
}

DOI: $h$ ttp://

dx.doi.org/10.3126/

jcmsn.v12i3.16015

Article received: June $1^{\text {st }}$

2016

Article accepted: Sept $6^{\text {th }}$

2016

\begin{abstract}
Background \& Objectives: Acute anterior shoulder dislocation needs prompt reduction of the dislocation. The ideal reduction method should be simple, fast, effective and non- traumatic, with minimal pain, and should not cause further injury to the affected shoulder. Intra-articular local lignocaine injection is a means of achieving analgesia with less complication, and allowing prompt patient discharge of patient after reduction. The study was conducted with objective to evaluate the effectiveness of intra-articular lignocaine for reduction of acute anterior shoulder dislocation. Materials \& Methods: Twenty- one cases of acute anterior shoulder dislocation were reduced using intra-articular local lignocaine injection as a method of analgesia by modified Hippocrates method. Results: The mean age was 44.71 years \pm SD 20.14 while 11 cases were reduced with one to six hours of injury. Pain assessed through application of a visual analogue scale during the maneuver revealed scores ranging from two to eight with mean score of $4.29 \pm$ SD 1.55.

Conclusion: This method is not only safe and effective but also reduces hospital stay and has negligible adverse effects making it a popular choice for most orthopedists.
\end{abstract}

Key words: Acute anterior shoulder dislocation; intra-articular local lignocaine injection; visual analogue scale

Citation: Kandel M, Thapa SK, Marasini R, Thapa S, Dhakal S, Shrestha R. Intra-articular lignocaine as a means of analgesia during manual reduction of acute anterior shoulder dislocation. JCMS Nepal. 2016;12 (3):108-10.

\section{INTRODUCTION}

The shoulder joint is the most commonly dislocated joint with majority occurring in an anterior direction. An acute shoulder dislocation is an orthopedic emergency so it should be reduced to its anatomic position as soon as possible. ${ }^{1}$ Although several reduction techniques with or without analgesia have been described, ideal reduction method should be simple, quick, effective and nontraumatic, with least pain and complications and cheap. $^{2}$

Recently, intra-articular lignocaine (IAL) has been advocated as a means of providing analgesia during manual reduction of acute anterior shoulder dislocation (AASD). ${ }^{2,3,4}$ Some authors have suggested that this would be an excellent choice for improved analgesia, in addition to its low costs and low complication rates. It may permit avoidance of sedative agents while achieving, acceptable degrees of analgesia without intravenous in patients who lack easily obtainable intravenous access, monitoring including monitoring of oxygen saturation and electrocardiography may not be required during or after reduction, significantly shorter emergency room (ER) stay. There may be anxiety among patients receiving IAL may interfere with joint reduction, difficulty in determining the correct intra-articular placement of lignocaine, lack of substantial muscle relaxation, potential risk of septic arthritis and systemic lignocaine toxicity. $5,6,7,8$ Hence this study was conducted to assess the effectiveness of intra-articular lignocaine for reduction of acute anterior shoulder dislocation in terms of ease of reduction and amount of pain caused by the procedure.

\section{MATERIALS AND METHODS}

Twenty-one patients of AASD who presented in the 
ER of Bharatpur Government Hospital Bharatpur, between July 2015 to April 2016 were included for the study. The inclusion criteria included the patients between 15 to 70 years age with isolated anterior dislocation of shoulder without neurovascular injuries.

Clinical tests such as Duga's test, Hamilton ruler test and loss of deltoid bulge; and radiographic findings showing total loss of articular congruity between the humeral head and glenoid cavity were used for the diagnosis.

Under all aseptic precautions about $15 \mathrm{ml}$ of $1 \%$ lignocaine was injected into the shoulder joint with a 20 -gauge needle immediately below the poserolateral angle of the acromion directing towards the glenoid cavity. The reduction was attempted about five minutes after intra- articular injection to achieve adequate analgesia and muscle relaxation. The modified Hippocrates traction and countertraction method was performed for all the cases with a bed sheet placed under the patient's armpit. After successful relocation, the shoulder was immobilized in internal rotation with the help of a shoulder immobilizer for three weeks in patients younger than 30 years and one week in patients above 30 years. The pain during the reduction was assessed through application of a visual analogue scale (VAS). All the statistical analyses were done through SPSS for Windows, Version 22.0.

\section{RESULTS}

In our study the age of the patients ranged from 17 to 70 years with mean age of 44.71 years \pm 20.14 SD. There were 15 males and six females. Dominant side was dislocated in 10 cases while non - dominant side was involved in 11 cases. There was only one case of recurrent shoulder dislocation while the remaining being primary dislocation. Most of the cases (11) were reduced within one to six hours of injury while six cases were reduced within first hour, three cases within seven to 24 hours and one case was reduced after 24 hours. Pain was assessed through application of VAS during the maneuver revealed scores ranging from two to eight with mean score of $4.29 \pm 1.55 \mathrm{SD}$ ( $\mathrm{p}$ value 0.049 ). During the whole observation period of three weeks we did not notice any superficial or deep infection, any neurovascular injuries or lignocaine toxicity. All the patients were discharged from the ER on the same day after reduction.

\section{DISCUSSION}

IAL as a means of analgesia for manual reduction of AASD has become the primary method of choice for orthopedic surgeons due to the fact that it not only provides acceptable degrees of analgesia without intravenous access and patient monitoring, but is also associated with significantly shorter ER stay, lower complication rate and cost. Excellent results have been reported in numerous studies when this method was adopted. ${ }^{2,47}$ A recent metaanalysis and a Cochrane review have shown that intra-articular analgesia permits the same pain control and reduction success as intravenous agents, while markedly reducing time in the emergency department and treatment cost. There were fewer adverse effects and no cases of infection. ${ }^{5}$ Although various amount and concentration of lignocaine have been used for intra-articular injection in different studies, we have used $7.5 \mathrm{ml}$ of $2 \%$ lignocaine diluted with $7.5 \mathrm{ml}$ of water for injection. Four patients rated pain at six or above in VAS which could be attributed to lack of analgesia probably due to lignocaine injection outside the joint and different pain thresholds in those patients. In our study reduction was defined as 'easy' for those that required very little physical time and effort, and 'tough' for those that required significant physical effort or time close to requiring general anesthesia or multiple efforts to reduce. All the dislocations were easy to reduce except in six cases where either pain or anxiety made it tough. All the dislocations were successfully reduced by modified Hippocrates method in the ER while two cases needed two attempts at reduction. There are theoretical risks of septic arthritis and lignocaine during IAL injection but not a single case have been reported till date.

\section{Table 1: Visual Analogue Score}

\begin{tabular}{cccc}
$\begin{array}{c}\text { Visual } \\
\begin{array}{c}\text { Analogue } \\
\text { Score }\end{array}\end{array}$ & $\begin{array}{c}\text { No. of } \\
\text { patients }\end{array}$ & $\begin{array}{c}\text { Mean } \pm \\
\text { S.D. }\end{array}$ & p value \\
1 & 0 & & \\
2 & 1 & & \\
3 & 7 & & \\
\hline 4 & 6 & & \\
5 & 2 & & \\
6 & 3 & $4.29 \pm 1.55$ & 0.049 \\
\hline 7 & 1 & & \\
\hline 8 & 1 & & \\
9 & 0 & & \\
10 & 0 & & \\
\hline
\end{tabular}




\section{CONCLUSION}

Although further trails comparing IAL with other methods of analgesia should be undertaken, easy application without the need for monitoring the patient, no complications like central nervous system depression and cardio-respiratory decompensation, prompt discharge from ER with acceptable degree of analgesia and cost effectiveness makes it very effective method of pain relief.

\section{REFERENCES}

1. Kwon YW, Kulwicki KJ, Zuckerman JD. Glenohumeral Joint Subluxations, Dislocations, and Instability. In: Bucholz RW, Heckman JD, Court-Brown CM, Tornetta P, editors. Rockwood And Green's Fractures, 7th edition. Philadelphia: Lippincott Williams \& Wilkins;2010.p.1165210. PMID: 20803118.

2. Tamaoki MJS, Faloppa F, Wajnsztejn A, Netto NA, Matsumoto MH, Belloti JC. Effectiveness of intra-articular lidocaine injection for reduction of anterior shoulder dislocation: randomized clinical trial. Sao Paulo Med J.2012; 130(6):367-72. DOI: 10.1590/S151631802012000600003. PMID: 23338733.

3. Fitch RW, Kuhn JE. Intraarticular Lidocaine versus Intravenous Procedural Sedation with Narcotics and Benzodiazepines for Reduction of the Dislocated Shoulder: A Systematic Review. Acad Emerg Med.2008;15(8):703-8. DOI: 10.1111/j.1553-2712.2008.00164.x. PMID:18783486.

4. Sama HD, Maman AFOB, Kabore RAF, Belo M. Observational Study of Intra-Articular Lidocaine for Management of Shoulder-Dislocation at Sylvanus Olympio University Teaching Hospital, Togo. Int J Clin Anesthesiol.2014;2(2):1028.

5. Wakai A, O'Sullivan R, McCabe A. Intra-articular lignocaine versus intravenous analgesia with or without sedation for manual reduction of acute anterior shoulder dislocation in adults. Cochrane Database of Systematic Reviews 2011, Issue 4. Art. No.: CD004919. DOI: 10.1002/14651858.CD004919.pub2.PMID: 21491392.

6. Cheok CY, Mohamad JA, Ahmad TS. Pain Relief for Reduction of Acute Anterior Shoulder Dislocations: A Prospective Randomized Study Comparing Intravenous Sedation With Intraarticular Lidocaine. J Orthop Trauma.2011;25:5-10. DOI: 10.1097/ BOT.0b013e3181d3d338. PMID: 21164304.

7. Paudel K, Pradhan RL, Rijal KP. Reduction of Acute Anterior Shoulder Dislocations under Local Anaesthesia A Prospective Study. KUMJ. 2004;2(1): 13-7.

8. Harnroongroj T, Keeratipongpaiboon K, Lertudomphonwanit T, Harnroongroj T. Sedative-free Reduction of Acute Anterior Shoulder Dislocation Saves Postreduction Service Time in the Emergency Room. J Surg Apr.2011;32:49-52. 